\title{
Peer support and global mental health
}

\author{
B. Puschner \\ Department of Psychiatry II, Ulm University, Ulm, Germany
}

Received 5 March 2018; Accepted 6 March 2018; First published online 12 April 2018

Key words: Peer support, global mental health, implementation research, service user involvement.

Peer support, i.e. persons with a lived experience of mental illness and recovery supporting others living with mental health problems, is an empirically validated resource-oriented therapeutic promoting recovery (Priebe et al. 2014; Slade et al. 2014). During the last decades, peer support has been implemented to varying degrees in mental health services of many high income countries (Mahlke et al. 2014). At the same time, the burden of mental disorders and the treatment gap between those in need and those actually receiving formal mental health care is especially prominent in low and middle income countries (Kohn et al. 2004; Patel et al. 2007). The knowledge of people with a lived experience of mental illness who de-stigmatise mental illness, offer alternative viewpoints in understanding clients and strengthen a person-focused (rather than a pathological-focused) discourse is an untapped resource in global mental health.

Two editorials in this issue of Epidemiology and Psychiatric Sciences describe peer support for people with mental illness in a high and a lower middle income country.

For Israel, Moran (2018) describes a stage-like development of mental health services over the last 50+ years - from an institutional/medical model towards recovery-orientation, and points to the vital role of the consumer movement for this evolution. Endorsed by the Israeli government, over the last years a rich variety of peer support services have become an integral part of Israel's mental health service provision. Challenges remain, such as tackling peer support workers' role dilution and finding their 'right' place in different parts of the service system. However,

Address for correspondence: Dr B. Puschner, Department of Psychiatry II, Ulm University, Ulm, Germany.

(Email: bernd.puschner@bkh-guenzburg.de) these are problems that peer support advocates in most other parts of the world would wish for.

When following Moran's idea of a stage-like development of mental health services, implementation of peer support in India as described by Pathare et al. (2018) appears to happen at a rather early level. Major obstacles are legislators and other stakeholders adhering to a medical model of mental illness, and the lack of an active consumer movement.

Both editorials give valuable insights into the factors hindering or fostering the practice of peer support. Despite differences of the organisation of mental health service provision in Israel and India, common mechanisms driving the successful implementation of peer support may be identified: a critical number of active (former) service users and/or carers expressing clear disenchantment with existing services, and the transformation of such a 'movement' into political action by exerting influence on health policy decision makers. This appears to be a global phenomenon (Ennis \& Wykes, 2013; Semrau et al. 2016), and in turn implies that the effect of top-down processes on implementation of recovery-oriented interventions initiated by researchers or outside 'activists' may be limited.

By definition, consumer involvement is an integral part of peer support because the intervention is provided by peers. Hence, peer support may especially suited to be scaled up and to reduce the treatment gap in high-, middle- and low-resource settings. Authors of the two editorials and this comment are part of the UPSIDES ('Using Peer Support In Developing Empowering Mental Health Services') project which has started in January 2018 and is funded by the European Union and the Global Alliance of Chronic Diseases (GACD). UPSIDES will actively involve and empower service users to generate system changes towards patient-centeredness, recovery orientation and community participation. In an effort to avoid pitfalls of Global Mental Health 
initiatives (Whitley, 2015), UPSIDES will strive to establish effective north-north, north-south and south-south learning and collaboration in order to find ways to effectively collaborate with and to reinforce existing initiatives. By building on the expertise of people with personal experience of mental illness, this cooperation of mental health researchers, providers and users at nine study sites in seven countries in Europe, Africa and Asia will be working towards transforming health systems in order to realise mental health as a human right.

\section{Financial support}

UPSIDES has received funding from the European Union's Horizon 2020 research and innovation programme under grant agreement No 779263. This article reflects only the author's view. The Commission is not responsible for any use that may be made of the information it contains.

\section{Conflict of interest}

None.

\section{References}

Ennis L, Wykes T (2013). Impact of patient involvement in mental health research: longitudinal study. British Journal of Psychiatry 203, 381-386.
Kohn R, Saxena S, Levav I, Saraceno B (2004). The treatment gap in mental health care. Bulletin of the World Health Organization 82, 858-866.

Mahlke CI, Krämer UM, Becker T, Bock T (2014). Peer support in mental health services. Current Opinion in Psychiatry 27, 276-281.

Moran GS (2018). The consumer movement and peer providers in Israel. Epidemiology and Psychiatric Sciences, online first.

Patel V, Araya R, Chatterjee S, Chisholm D, Cohen A, de Silva M , Hosman C, McGuire H, Rojas G, van Ommeren M (2007). Treatment and prevention of mental disorders in low-income and middle-income countries. Lancet 370, 991-1005.

Pathare S, Kalha J, Krishnamoorthy S (2018). Peer support for mental illness in India: an under-utilised resource. Epidemiology and Psychiatric Sciences, online first.

Priebe S, Omer S, Giacco D, Slade M (2014). Resource-oriented therapeutic models in psychiatry: conceptual review. British Journal of Psychiatry 204, 256-261.

Semrau M, Lempp H, Keynejad R, Evans-Lacko S, Mugisha J, Raja S, Lamichhane J, Alem A, Thornicroft G, Hanlon C (2016). Service user and caregiver involvement in mental health system strengthening in low- and middle-income countries: systematic review. BMC Health Services Research 16, 79 .

Slade M, Amering M, Farkas M, Hamilton B, O'Hagan M, Panther G, Perkins R, Shepherd G, Tse S, Whitley R (2014). Uses and abuses of recovery: implementing recovery-oriented practices in mental health systems. World Psychiatry 13, 12-20.

Whitley R (2015). Global mental health: concepts, conflicts and controversies. Epidemiology and Psychiatric Sciences 24, 285-291. 